treatment, but have to meet the expectations of the whole group. This proves to be a powerful sanction; on occasions achieving dramatic changes. Nor is it merely a punitive force. It can also be a source of sincere praise from peers, as a reward for even minor changes, as they will appreciate the enormous efforts needed to overcome social inhibitions and breaks with easy excuses. In much the same way, members can support one another to maintain their resolution to avoid further offending, and it could be argued that this is sufficient justification for allowing a long-term supportive role.

\section{Ideas for the future}

Having devised the group to be a short-term treatment facility, we were not attentive enough to the needs of a sub-group of older, socially unskilled and isolated men who seem to value ongoing support in their lives. Perhaps this needs to take place over years while, it is hoped, they slowly move in the right direction. These latter individuals could be catered for in a second group, meeting less frequently, and, as it should be more stable, it might be managed by one therapist.

Without question, we have a duty to evaluate the benefits, successes and failures of our treatment programme. Ideally, we also need to compare its efficacy with the other approaches conducted elsewhere. We are in the process of attempting to measure our results, but are only too aware that such research requires a great deal of extra resources and commitment which is difficult for most workers to give. Yet, until firm evidence is to hand, we could either be wasting our time in providing this service or, alternatively, should be arguing for others to provide similar treatment facilities.

In any case, whatever the value, we have all enjoyed working on the project and can wholeheartedly recommend it as a challenging, exciting and rewarding experience.

\section{Acknowledgements}

We wish to thank all those who referred cases, our secretarial staff for their help, Dr Angus Campbell for his support and encouragement, and all the staff at the Minshull Street Probation Office for putting up with us!

\section{References}

${ }^{1}$ Mickow, G. \& Benson, M. (1973) Group therapy for sex offenders. Social Work (New York), 18, 98-100.

${ }^{2}$ SHAw, R. (1978) The persistent sexual offender-control and rehabilitation (a follow-up). Probation Journal, 25, 61-63.

${ }^{3}$ HoBBs, M. (1980) Group therapy with sexual offenders. Australian Journal of Clinical Hypnotherapy, 1, 105111.

\title{
The management of potentially dangerous patients in the community
}

\author{
Enda Dooley, Senior Registrar in Forensic Psychiatry, The Maudsley Hospital, London \\ SE5 (formerly Senior Registrar in Psychiatry, Broadmoor Hospital, Crowthorne, \\ Berks.)
}

With the accelerating drive towards the running down of large psychiatric hospitals and the trend towards the care and management of psychiatrically ill people in the community, it is inevitable that a small proportion of these people will be unable to cope with this change. Some patients may have a long history of violent behaviour which has been coped with in hospital. Others may have been able to cope within the 'asylum' environment but, when placed in a community which is little better able to cope with them than they are with it, regress to violent behaviour when faced with unaccustomed stress.
In attempting to care for these patients in the community, it should be borne in mind that not only are they themselves more vulnerable, but those who are expected to provide care, e.g. families, community nurses, hostel staff, GPs, social workers, etc., are placed in a more demanding situation. At a time when increasingly difficult patients are being moved to the community, staff service resources are being cut down. This increases the anxiety of those who are expected to provide this care.

It is important to bear in mind that we live in a society which is increasingly violent. The majority of 
violent behaviour is perpetrated by people who are not mentally ill. Furthermore, relatively few people who are mentally ill will behave violently. The relationship of violent behaviour to psychiatric illness falls into three areas:

(a) Violent behaviour may occur as a result of mental illness. Treatment of the illness leads to a diminution or extinction of the violent behaviour.

(b) Violent behaviour may occur in those who are mentally ill but the treatment of the illness has little or no effect on the behaviour. Often in these cases the violence is a manifestation of the underlying personality rather than being due to the illness.

(c) As mentioned above, violent behaviour may be manifested by those in whom there is no evidence of mental illness.

A discussion of the features of various mental disorders associated with violent behaviour has been undertaken elsewhere. ${ }^{1,2,3}$ Nevertheless, certain salient features bear repeating. Schizophrenic patients who behave violently often have secondary diagnoses, e.g. substance abuse, mental impairment, epilepsy, etc. which are themselves associated with violent behaviour. There is an unfortunate tendency to label violent or difficult schizophrenic patients as being 'psychopathic', suffering from 'antisocial personality disorder', etc. and to justify not admitting or even not offering treatment on the basis that the condition is 'untreatable'. Aggressive behaviour tends to be related to the severity of psychotic symptoms rather than to overt hostility. In those suffering from paranoid schizophrenia, violence often tends to be planned and in line with a delusional belief and may be directed at a specific individual. Conversely, violent behaviour in non-paranoid schizophrenics reflects the disorganised psychotic state and is often less focused.

Morbid or pathological jealousy may have a number of causes. Separation is often advised to protect a wife or partner; but it is worth remembering that subsequent partners may be equally at risk.

Depression is mainly associated with suicide, which can be viewed as inwardly directed violence. Very rarely psychotic depression with nihilistic delusions may, if undetected or untreated, result in very severe violence, quite often to immediate family members. Though hypomanic patients may show marked agitation, irritability, and anger, they tend to show relatively little assaultiveness. This may be related to the fact that some degree of impulse control is retained.

In the mentally impaired, violence usually occurs as a response to some stress or frustration where the limited coping skills of the individual are overcome. On occasions an inept or inappropriate social approach may be rebuffed. Persistence may cause fear or resistance by the potential victim and this may provoke some form of assault.

\section{Management in the community}

(a) It is important to know the patient so that any change in attitude or demeanour may be noted.

(b) If possible, staff should avoid going into a patient's home alone if they feel unsafe.

(c) It is always better to withdraw rather than trying to control the violent patient alone. This may not be possible, however, if there are others, e.g. children, at risk.

(d) If it is felt that a patient may strike out, always keep at arm's length and try and manoeuvre to a route of escape. In certain situations, such as kitchens, it is important to be aware of the need to keep out of range of other weapons, e.g. knives, sweeping brushes, etc.

(e) The most vulnerable time is when you begin to speak. At this time the patient feels most threatened by you and you have not yet had the opportunity to establish any kind of rapport. No matter how inaccessible patients appear, it is better to try and gain their trust by telling them at all times what is happening and why. This is especially true if it is necessary to enlist the help of the police.

(f) The question of when to involve the police remains somewhat contentious. In general, if it is considered that physical restraint of a violent patient may be required the police should be involved, both to minimise the risk of injury and to avoid the risk of staff being charged with assault.

\section{Medico-legal issues}

If we accept that the management of the mentally ill in the community will lead to more episodes of violent behaviour, then this is going to have increasing medico-legal implications for the practice of psychiatry. One only has to look at the United States and Canada ${ }^{4,5}$ to see what has already occurred there.

Firstly, there is going to be a need for clearer health authority or hospital policy covering such areas as when and how a violent patient should be admitted, what precautions should be taken to protect staff and the public, when should the police be involved and who should be responsible for involving them. In situations where staff sustain injury and plan to seek compensation, there may be a legal need for a form of statement or complaint to be made to the police. If violence occurs within a hospital, consideration may have to be given to bringing charges against the patient. It cannot be taken for granted just because someone has a history of mental illness that this excuses him from all responsibility for his actions.

Increasingly the medical defence organisations are recognising that psychiatry is not a low risk speciality. If experience in America follows here then doctors, community care staff, and hospitals will face increasing risk of legal action from a variety of 
sources. Patients may sue claiming assault, claiming that they have sustained injury, that they have been illegally or incorrectly restrained, or that care staff have been negligent in not preventing self-injury by the patient.

Families and third parties may sue for failure to treat a patient appropriately, so allowing him to injure somebody or to injure himself. Staff may also be faced with action over failure to warn people who are subsequently assaulted. If this should seem farfetched or unreasonable, one only has to read an account of the various decisions in the Tarasoff case ${ }^{6}$ in the United Stated to see the extent to which therapist responsibility can extend.

In discussing the problems posed in the management of violent patients in the community, it is all too easy to overlook the extra strain these patients place on care staff, especially community psychiatric nurses and social workers. Staff working in the community tend to be relatively isolated. There is a tendency to under-report threats or incidents of violence by patients on the basis that this reflects some kind of failure on the part of the staff concerned. This not only applies in the community but also in hospital care. When staff are injured there tends to be little support from superiors and employing authorities, and little encouragement to discuss the effect of an assault by a patient on the willingness or ability of staff to cope with the demands of the job. All assaults by patients on staff, no matter how trivial, should be reported and thoroughly reviewed, to prevent unnecessary repetition and to allow ventilation of staff fears and concerns in dealing with this difficult group of patients.

\section{Possible safeguards}

In many cases violent behaviour by psychiatric patients living in the community occurs when there is a relapse in the illness. This is especially true in schizophrenic patients who either fail to attend outpatient appointments or refuse to accept treatment. To date there has been no mechanism to ensure that a patient will continue on treatment in the community when he is unwilling to accept it. Currently the treatment provisions of section 3 of the Mental Health Act 1983 apply only to patients in hospital. Patients who are subject to a Guardianship order do not have to accept treatment (only ". . . to attend at places and times so specified ..."). The importance of avoiding unnecessary relapse is particularly relevant in patients who have a history of violence, or are likely to behave violently when ill, as episodes of violence only tend to alienate carers and community and so place in jeopardy the precarious independence these patients have managed to achieve. One step which may help to avoid unnecessary relapse due to default in treatment is the introduction of a Community Treatment Order as proposed by the Royal College of Psychiatrists. ${ }^{7}$ This would apply only to those coming under the category of mental illness, whose illness has in the past responded to medication and where there is a substantial likelihood of relapse unless treatment is instituted or continued. This order would be particularly relevant to those likely to be violent to themselves or to others, as application would be made on the grounds that treatment would be "necessary for the health and safety of the patient or for the protection of others". It would appear self-evident that any step that promotes the mental health of a patient under the least restrictive conditions and lessens the possibility of compulsory admission, especially where violent behaviour has occurred during epsiodes of illness, merits serious consideration.

\section{Acknowledgement}

I am grateful to Dr John Hamilton for his helpful comments on the manuscipt.

\section{References}

${ }^{1}$ FotTrell, E. (1981) Violent behaviour by psychiatric patients. British Journal of Hospital Medicine, 25, 28-38.

${ }^{2}$ Krakowski, M., Volavka, J. \& Brizer, D. (1986) Psychopathology and violence: A review of literature. Comprehensive Psychiatry, 27, 131-148.

${ }^{3}$ CURTIS, J. M. (1985) Considerations in diagnosis and management of violent behaviour. Psychological Reports, 57, 815-823.

${ }^{4}$ Stone, A. A. (1984) Law, Psychiatry and Morality. Washington: American Psychiatric Press.

${ }^{5}$ DiCKENS, B. M. (1986) Legal issues in medical management of violent and threatening patients. Canadian Journal of Psychiatry, 31, 771-780.

${ }^{6}$ Tarasoff v Regents of Univs of California (1974), 529 P.2d 553 (Cal. Sup. Ct.) and (1976), 551 P.2d 334 (Cal. Sup. Ct.).

${ }^{7}$ Royal College of Psychiatrists (1987) Community Treatment Orders-A Discussion Document of the Royal College of Psychiatrists. 